\title{
Governamentalidade e pilotagem na antiga Grécia: uma análise foucaultiana
}

\author{
Governamentality and piloting in ancient Greece: \\ a foucaultian analysis
}

\author{
Fabiano Incerti \\ https://orcid.org/0000-0001-6292-0011 - E-mail: fabiano.incerti@yahoo.com
}

\section{RESUMO}

A partir do pensamento de Foucault, este artigo pretende mostrar alguns pontos de intersecção, na antiga Grécia, entre a pilotagem, vinculada à metáfora navegação e a noção de governamentalidade. Passando pelo governo de si mesmo, pelo governo político e pela medicina, que são para o pensador francês, as três atividades que se aproximam da arte de comandar um navio, veremos como esta ocupou um espaço significativo na literatura e na vida social grega, com alcances e funções bem definidas. Com inteligência, destreza e, principalmente, sabendo reconhecer a direção dos ventos e a orientação que indicam os astros, o piloto é aquele que possui a tékhne capaz de conduzir a embarcação, que primeiramente é o próprio sujeito e depois que são os outros, até um porto seguro.

Palavras-chaves: Pilotagem. Governamentalidade. Michel Foucault.

\begin{abstract}
Based on Foucault's thinking, this article intends to show intersecting points in Ancient Greece, between piloting, connected to the navegation metaphor and the notion of governamentality. Going through one's own government, political government and medicine, which to the French thinker, are the three activities that come closest to the art of driving a boat, we see how this took up significant space in Greek literature and social life, with well-defined ranges and functions. With intelligence, skill, and especially knowing how to recognize wind direction, and
\end{abstract}


orientation from stars, the pilot is whoever has enough techne to lead the ship, which primarily is the subject itself and afterwards, it's the other, until an eventual safe haven.

Keywords: Piloting. Governamentality. Michel Foucault.

\section{Introdução}

Pode parecer um tema menor, mas a verdade é que o problema da pilotagem, vinculada à metáfora navegação, ocupou um espaço significativo na literatura e na vida social grega, com alcances e funções bem definidas. Vemos isso, por exemplo, numa importante análise na qual Marcel Detienne e Jean Pierre Vernant vinculam inteligência e navegação, em que se destaca a noção de $M \tilde{T} T \iota^{1}{ }^{1}$. A destreza do piloto é parte de uma inteligência de múltiplas facetas: o $\gamma v \omega ́ \mu \eta$

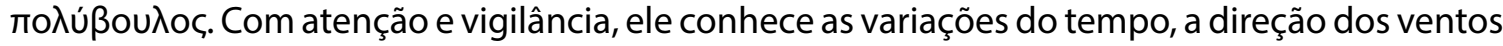
e o rumo que indicam os astros. Carregando a responsabilidade de levar, com segurança, o navio ao porto, com golpes de leme o piloto corrige os afastamentos da embarcação, a endireita e a dirige "por uma caminhada cheia de desvios, em traçados oblíquos e circuitos tortuosos, desenhados pelos movimentos do mar e pelos caprichos do vento, a inteligência sabe conduzir o navio, sem jamais se desviar da rota que ela de antemão meditou seguir" (DETIENNE; VERNANT, 2008, p. 203-204). Por isso que "a navegação está em primeiro lugar na lista de empreendimentos do ser 'cheio de recursos', паvтопо́рос" (DETIENNE; VERNANT, 2008, р. 202).

Todavia, comandar um barco na antiguidade superava em muito apenas uma questão de domínio técnico. Gustave Glotz nos mostra que quando a dimensão ordálica invadia o direito, viajar pelo mar sem sofrer nenhum acidente significava presunção de inocência e se tais travessias bem-sucedidas acontecessem de forma recorrente transformavam-se em prova de impecável virtude. Por isso mesmo, nos tribunais, tais habilidades marítimas representavam um argumento de força singular para a defesa de um acusado (GLOTZ, 1904, p. 67).

O que sabemos hoje é que a competência a frente de um leme alcançou também o campo do político, pois as aptidões do piloto de um navio eram também as esperadas de um governante. Um primeiro deslizamento conceitual, nesse sentido, se identifica do ponto de

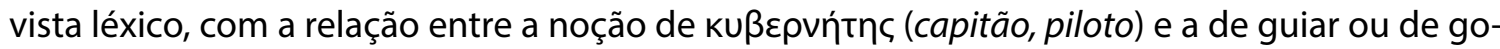
vernar. Encontramos tal associação tanto no consagrado $A$ Greek-English Lexicon de Liddel e Scott (1996, p. 1004) bem como no A Patristic Greek Lexicon de Lampe (1961, p. 784). Daremberg et Saglio, por sua vez, em seu Dictionnaire des Antiquités Grecques et Romaines (1919, p.16731674) mostram como o responsável pela embarcação empresta para o latim o sentido de guber-

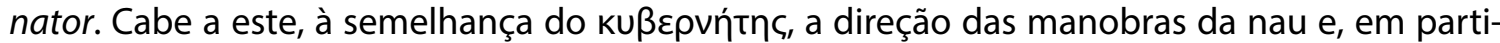
cular, o controle do leme. Ele realiza a observação do céu, que permite identificar, junto com o tempo e os ventos, a posição do navio no mar e fixar a rota a seguir. Conhece o mar com suas águas rasas e recifes, a costa e os portos.

\footnotetext{
1 "O homem que possui a Mñtıs está sempre prestes a saltar; ele age no tempo de um relâmpago. Isso quer dizer que ele cede, como fazem comumente os heróis homéricos, a um impulso súbito. Ao contrário, sua MñTıç soube pacientemente esperar que se produzisse a ocasião esperada. Mesmo quando ela procede de um impulso brusco, a obra da Mñtıç situa-se nos antípodas da impulsividade. A Mñtıç é rápida, pronta como a ocasião que ela deve apreender no voo, sem deixá-la passar [...] Em vez de flutuar lá e cá ao sabor das circunstâncias, ela ancora profundamente o espírito no projeto que ela maquinou antes, graças a sua capacidade de prever, além do presente imediato, um pedaço mais ou menos espesso do futuro" (DETIENNE; VERNANT, 2008, p. 203-204).
} 
Mas que tanto na cultura grega como na cultura latina tenha havido semelhança entre o trabalho de um capitão do mar e um governante político não nos deve parecer estranho, já que ambos são responsáveis - tomando decisões e dando ordens - por comunidades de pessoas que estão sob seu governo. O primeiro cuida de sua embarcação e tem como objetivo navegar com habilidade e inteligência, para enfim atracar, com segurança, no destino almejado. Já o segundo dirige seu país com objetivo de fazê-lo prosperar, zelando para que todos que vivem nele sintam-se, a exemplo da tripulação de um navio, igualmente protegidos.

Muitos autores antigos, como forma de discutir problemas políticos e até mesmo práticas de governo, compararam metaforicamente as cidades-estados gregas a navios e seus governantes a pilotos, sejam estes bons ou ruins. Talvez os primeiros versos que fazem tal relação são as do poeta lírico Alceu de Mitilene no século VI a. C. dirigidas à administração de Pítaco.

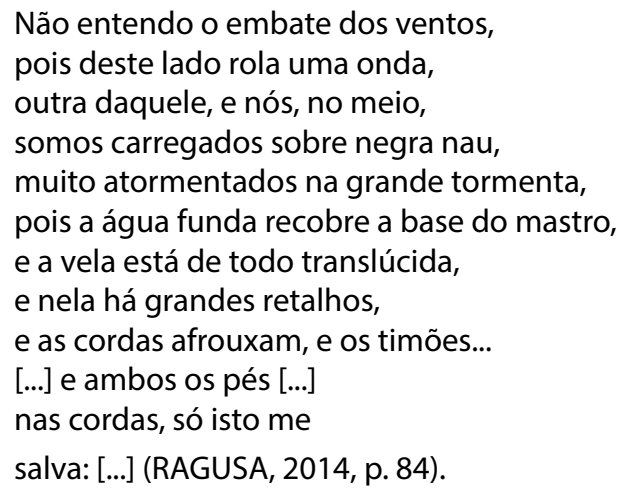

Também em outro poeta lírico do mesmo período, Teógnis, encontramos navegação e política colocados sob um mesmo registro simbólico.

\begin{abstract}
Se eu tivesse riquezas, Simonides, como as que já tive, não me afligiria por estar em companhia de homens de bem. Mas agora, embora eu compreenda, as coisas me escapam; estou mudo, por causa da pobreza; eu saberia melhor ainda do que muitos, porque somos agora levados com as velas brancas recolhidas, tendo sido lançados para fora do mar de Meios, durante a noite sombria; e eles não querem despejar a água acumulada no fundo do navio, quando o mar transpõe as duas bordas. Muito difícil será que se salvem, da maneira como se comportam; afastaram do comando o prudente piloto, que era hábil em sua vigilância; apoderam-se violentamente das riquezas, a ordem desapareceu e não há mais partilha justa ao meio; os carregadores comandam, os homens inferiores são superiores aos homens de bem. Estou assustado, que de nenhum modo a onda engula o barco. Que esses enigmas sejam insinuados por mim aos homens de bem; entendê-los-ia um homem inferior, se fosse sábio (ONELLY, 2009, p. 142-143).
\end{abstract}

Enquanto em Sete contra Tebas, de Ésquilo, é a água da sentina, impedida de entrar, que representa o inimigo (795-796) ${ }^{2}$, na República, Platão dedica um longo trecho para relacionar o problema do governo com a função do piloto de um navio. Nesta importante passagem, Sócrates pretende mostrar em que consiste o sofrimento dos melhores homens da cidade, ou seja, os filósofos e para isso se utiliza de uma metáfora onde marinheiros maus e perversos tomam o leme do navio. Estes são, para ele, comparados aos governantes, por considerarem inúteis os filósofos sábios, que são, por sua vez, os verdadeiros pilotos.

\footnotetext{
2 Para esta citação direta do texto de Ésquilo utilizamos, entre parênteses, os números dos versos compatíveis com a obra contida nas referências bibliográficas deste trabalho.
} 
[...] Imagina, pois, que acontece uma coisa desta espécie, ou em vários navios ou num só: um armador, superior em tamanho e em força a todos os que se encontram na embarcação, mas um tanto surdo e com a vista a condizer, e conhecimentos náuticos da mesma extensão; os marinheiros em luta uns com os outros, por causa do leme, entendendo cada um deles que deve ser o piloto, sem ser jamais aprendido a arte de navegar nem poder indicar o nome do mestre nem a data do seu aprendizado, e ainda por cima asseverando que não é arte que se aprenda, e estando prontos a reduzir a bocados quem declarar sequer que se pode aprender, estão sempre a assediar o dono do navio, a pedir-lhe e a fazer tudo para que lhes entregue o leme; algumas vezes, se não são eles que o convencem, mas sim outros, matam-nos, a esses, ou atiram-nos pela borda fora; reduzem à impotência o verdadeiro dono com a mandrágora, a embriaguez ou qualquer ou qualquer outro meio; tomam conta do navio, apoderam-se da sua carga, bebem e regalam-se de comer, navegando como é natural que o faça gente dessa espécie; ainda por cima, elogiam e chamam marinheiros, pilotos e peritos na arte de navegar a quem tiver a habilidade de os ajudar a obter o comando, persuadindo ou forçando o dono do navio; a quem assim não fizer, apodam-no de inútil e nem sequer percebem que o verdadeiro piloto precisa de se preocupar com o ano, as estações, o céu, os astros, os ventos e tudo o que diz respeito à sua arte, se quer de fato ser o comandante do navio, a fim de governar, quer alguns o queiram quer alguns não o queiram - pois julgam que não é possível aprender essa arte e estudo, e ao mesmo tempo a de comandar uma nau. Quando se originam tais acontecimentos nos navios, não te parece que o verdadeiro piloto será realmente apodado de nefelibata, palrador, inútil pelos navegantes de embarcações assim aparelhadas? (PLATÃO, 2005, p. 272-273).

Levando em conta esta breve genealogia, nosso objetivo com este artigo é apontar para algumas intersecções existentes entre as noções de governamentalidade e pilotagem na Grécia antiga, tendo em conta os estudos de Michel Foucault dedicados ao assunto. Ainda que, no amplo espectro de seus escritos este seja um tema tangencial, defendemos com estas páginas que as habilidades do piloto são, para o pensador francês, aspectos imprescindíveis para o governo de si mesmo e dos outros.

Metodologicamente, tomaremos o caminho proposto pelo próprio pensador francês em seu curso A Hermenêutica do Sujeito, na qual ele indica três técnicas ou atividades que se aproximam da pilotagem na antiguidade greco-romana: governo sobre si mesmo, o governo político e a medicina. Faremos tal análise concentrando nossos olhares sobre os seus últimos cursos e estabelecendo um diálogo com autores antigos e contemporâneos, muitos destes seus interlocutores diretos nas pesquisas concernentes à filosofia greco-romana.

\section{A arte de pilotar-se}

Quando nos detemos no curso de Foucault de 1982, A Hermenêutica do Sujeito, pronunciado no Collège de France, destacamos uma importante dimensão na qual a atividade da pilotagem e o problema do cuidado de si se relacionam: a conversão de si. Na aula de 17 de março, ele começa por estabelecer dois importantes eixos que o "cuidar de si" assume quando comparado com o "velho' modelo socrático-platônico, que tem sua formulação máxima com o Alcebíades. Primeiramente, não se trata mais, pois, de considerá-lo numa "relação privilegiada com a pedagogia" (2006, p. 301), ou seja, a passagem da adolescência para a vida adulta, tampouco refere-se a algo que tenha uma "finalidade política", isto é, a preocupação por adquirir um "status particular no interior da sociedade" (2006, p. 301). Em segundo lugar, cuidar de si mesmo passa a ser "um princípio geral e incondicionado" (2006, p. 301); uma preocupação integral, que se estende por toda a vida do sujeito e não mais algo "para um momento determinado da vida" (2006, p. 301). 
Nesse contexto que Foucault introduz a problemática da conversão a si. Diferentemente do sentido cristão, que como ele mesmo defende implica uma renúncia de si em vista da salvação, na cultura helenística, converter-se é, antes de mais nada, "um movimento real, movimento real do sujeito em relação a si mesmo" (FOUCAULT, 2006, p. 302). Por isso, ela se traduz tanto em grego como em latim por expressões que designam algum tipo de deslocamento como "eph'heautàn epistréphein, eis heautàn anakhorefn, ad se recurrere, ad se redire, in se recedere, se reducere in tutum" (FOUCAULT, 2006, p. 302). Tais características levam o pensador francês a realizar outra diferenciação que se encontra no interior do que ele designa como uma condição "nua" do cuidado de si: deslocar-se não se resume num "prestar atenção a si mesmo, de dirigir o olhar a si ou de permanecer acordado e vigilante em relação a si" (2006, p. 302); é, sobretudo, "um certo deslocamento [...] do sujeito em relação a si mesmo. O sujeito deve ir em direção a alguma coisa que é ele próprio. Deslocamento, trajetória, esforço, movimento: é o que devemos reter na ideia de conversão a si" (2006, p. 302).

Esse é o ponto fulcral sobre o qual Foucault repousa o problema da pilotagem nessa aula. Ao comparar o movimento da conversão de si à metáfora da navegação, ele nos provoca a pensar quatro pontos: a) se navegar implica necessariamente o deslocamento de um ponto a outro, a conversão é, nesse sentido, o movimento do sujeito em direção a ele mesmo; b) se todo deslocamento marítimo tem uma meta, um objetivo a ser atingido, que é o porto, o ancoradouro, na conversão, esse lugar de chegada é o próprio sujeito; é ele o seu próprio porto, seu próprio ancoradouro; c) se o ponto de chegada é sempre o ponto de partida, na conversão o que se busca é essa "pátria" que é o si mesmo como lugar de origem; d) se o objetivo da navegação é chegar com segurança ao porto de origem, pois a viagem carrega consigo os riscos da travessia, a conversão a si implica também uma trajetória perigosa, sob percursos pouco ou mal conhecidos.

O que podemos concluir com a metáfora da navegação então, é que converter-se pode ser comparado a um "pilotar-se", na medida em que ambas exigem um tipo de técnica, de arte. Podemos ilustrar esta afirmação com um exemplo que encontramos na carta 85 que Sêneca dirige a Lucílio. Nela, ele pergunta: “Então não é nociva ao piloto a tempestade, que o impede de chegar ao porto, que torna inúteis todos os seus esforços, que o faz retroceder ou lhe destrói o aparelho e o impede de prosseguir?" (SÊNECA, 2004, p. 393). E a resposta do pensador estoico é que não, pois o bom piloto é testado em meio à tempestade, até porque, com bom tempo, "qualquer um pode ser piloto!" (2004, p. 393). É o mau tempo que coloca o timoneiro à prova, que aprimora a sua técnica e o que o faz se diferenciar do simples viajante.

O mesmo acontece com a conversão. São os perigos do percurso de retornar a si mesmo que colocam à prova o sujeito, sua técnica, sua arte. Localizada, segundo Foucault, exatamente entre a غ̇пॉб conjunto de atitudes que demandam do sujeito uma téxvn, tais como defender-se, armar-se, respeitar-se, honrar-se, possuir-se, ter deleite com o próprio eu. Por isso, ela não pressupõe uma súbita ruptura, ao modelo cristão, mas exige progressões diárias e pequenas correções. Da mesma forma, não prevê apenas o "virar-se na direção de si" da reminiscência platônica, mas reclama um olhar que compromete o sujeito para um movimento "do ser inteiro, que deve dirigir-se ao eu como único objetivo" (FOUCAULT, 2006, p. 262).

Se tomamos tais características da conversão - pequenas progressões e ter-se como único objetivo - encontramos novamente relacionadas à metáfora da pilotagem quando retornamos a Sêneca. Para o primeiro caso, na carta 14, ele diferencia exatamente o piloto temerário do piloto prudente. O primeiro "rompe subitamente" o mar, a ponto de não cuidar com os ventos traiçoeiros do Sul, enquanto o segundo "inquere dos conhecedores do local o sentido 
das correntes ou os indícios a tirar das nuvens", para então, com cautela, dirigir "a sua rota longe daquelas paragens tão tristemente famosas pelos seus vórtices" (2004, p, 46). Para o segundo caso, de colocar-se como único objetivo, o pensador estoico nos recorda, na carta 30, que "um bom piloto navega mesmo com a vela rasgada e, se os mastros forem derrubados, ainda assim escora os restos do barco até o fim da viagem" (2004, p. 111-112). Assim, para chegar ao porto com segurança, enfrentando todas as intempéries o piloto não promete aos viajantes o "bem-estar" na viagem, mas sim "o seu melhor esforço e o seu conhecimento da arte de conduzir um navio [...]" (2004, p. 393).

\section{Olhos atentos aos sinais: pilotagem e governo político em Édipo-Rei}

Um segundo lugar onde a pilotagem aparece com evidência no pensamento foucaultiano é no problema do governo político. Se nas páginas anteriores vimos como a arte de se autogovernar - dominar-se, converter-se - tinha como referência a arte de pilotar - dirigir a embarcação, conhecer as características e os desafios do mar - nos parágrafos seguintes veremos como tais características do piloto são esperadas daquele que deve governar a cidade. Ao mesmo tempo em que ele deve cuidar de si mesmo para assim cuidar dos outros, como nos indica a "velha" fórmula do cuidado de si presente no Alcebíades, o governante deve ser o piloto; aquele que com firmeza segura o leme e leva a cidade, que é o navio, para seu porto seguro.

Tomaremos aqui um exemplo bastante significativo onde Foucault desenvolve este tema e que confirma tais afirmações: a tragédia grega. Com a publicação, nos últimos anos, da quase totalidade de seus cursos no Collège de France e de outras conferências pronunciadas por ele em diferentes partes do mundo, em especial a partir de 1970, sabemos que a tragédia, em especial a peça Édipo-Rei de Sófocles, mereceu um amplo e, ao mesmo tempo, detalhado lugar de atenção em suas análises. A partir de 1970 até 1983, um ano antes da sua morte, foram ao menos seis grandes leituras do drama edipiano, sendo que uma delas - exatamente a do curso de 1983 - dividindo espaço com uma interpretação do ĺon de Eurípedes. Em suas análises, a imagem da pilotagem relacionada ao governo da cidade aparecerá, brevemente, em três conferências: Le savoir d'CEdipe, de 1972 pronunciado nos Estados Unidos; A verdade e as formas jurídicas, realizadas no Rio de Janeiro em 1973; e, por fim, Mal faire, dire vrai, curso dado pelo pensador francês na Bélgica em 1981.

Contudo, antes de mais nada, é importante retomarmos diretamente ao texto sofocliano, para mostrar como esta metáfora é emblemática no decorrer da trama. Nos versos iniciais, quando o rei se volta para a angústia de seu povo, Tebas é comparada a um navio: "Vapor de incenso assoma em meio à polis, assomam cantos fúnebres, lamentos" (4-5) ${ }^{3}$. Poucos versos depois, é o sacerdote, que implorando a intervenção de Édipo retoma a metáfora: “Naufraga a polis, podes conferi-lo" (22). A seguir, é Creonte, que no seu retorno de Delfos, recorda que Édipo é comparado ao antigo rei Laio, no comando do navio-cidade: "em tempos idos, tivemos

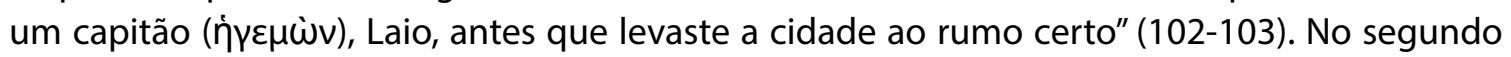
episódio, no embate com Creonte é o coro que oferece ao soberano um voto de fidelidade: "Já o disse e o repito, senhor, desprovido de razão eu seria, insensato, se te abandonasse, tu que pilotaste minha amada pátria, abalada, às águas da prosperidade guia-a, agora, se podes, a porto seguro" (690-697). Já no terceiro episódio, quando Édipo está diante do mensageiro e

\footnotetext{
${ }^{3}$ Para citações diretas e indiretas do texto de Sófocles utilizaremos, entre parênteses, os números dos versos compatíveis com as obras contidas nas referências bibliográficas deste trabalho.
} 
prestes a desenrolar a tragédia que assombra sua vida, é Jocasta que contesta: "todos trememos assombrados ao vermos desorientado o timoneiro do nosso barco" (923-924). Enfim, quando tudo está descoberto e o rei se encontra prisioneiro do destino que ele tentou de todas as formas escapar, é o coro que lamenta: "Célere, meu rei celebrado, no mesmo porto aportaste, esposo, rebento e pai" (1207-1209).

Quando nos detemos no problema da pilotagem nas análises de Foucault acerca de Édipo, é possível identificarmos pelo menos um traço em comum entre elas: o piloto do "navio" - o governante de Tebas - precisa "ver". Não por acaso, o pensador francês considera o mais famoso drama sofocliano como uma história do olhar; "[...] ele é o homem do ver, o homem do olhar e o será até o fim" (2008, p. 47). E como é recorrente entre alguns estudiosos da peça ${ }^{4}$, ele

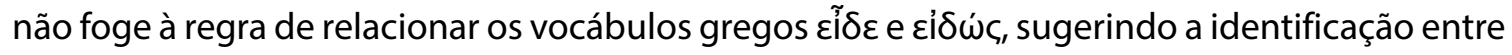
"conhecimento" e "visão" (2008, p. 47). Tal aspecto será algo determinante para o enredo, pois delimitará toda problemática em torno da inteligência e da ignorância. E se há algo que aproxima Édipo da pilotagem é exatamente a utilização do recurso da inteligência ( $\gamma v \omega ́ \mu \eta)$, que é próprio tanto da téxvn do piloto como daquele que governa a cidade. Para responder ao desafio que lhe é apresentado, de descobrir o motivo pelo qual Tebas está sendo atingida por uma

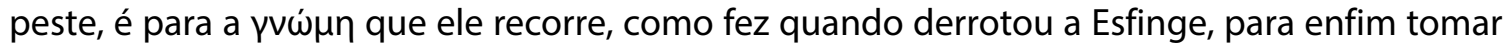
sua decisão: "Após madura reflexão, achei solução e esta eu pus em prática: a Delfos eu enviei Creonte" (p. 66-68).

O piloto tem seus olhos atentos ao mar e suas mãos sustentam a embarcação para que ela chegue protegida ao seu destino. E é este espírito de confiança, "naquele que na proa do navio abre os olhos para ver" (FOUCAULT, 2008, p. 47), que faz com que o sacerdote busque o rei de Tebas nos primeiros versos. E se Édipo é capaz de governar, é porque o seu saber solitário o conduz, como um piloto, "sem se apoiar no que se diz, sem ouvir ninguém", querendo "ver com seus próprios olhos" (FOUCAULT, 2008, p. 47).

Assim, a arte de pilotar e a arte de governar tem a característica de "descobrir os acontecimentos, através dos indícios" (FOUCAULT, 2018, p. 62) e por isso mesmo, não aceita e não se apoia nos desígnios estabelecidos pelos deuses. Trata-se, antes de mais nada, de um "saber político da pilotagem", que descobre a verdade a partir de elementos materiais e visíveis; como o piloto que em meio às intempéries advindas das tempestades em alto mar, demarca seu percurso pela observação das estrelas, pelo manejo da bússola e pela direção dos ventos.

Mas é este mesmo saber e esta mesma capacidade de ver que o levam a sua derrocada, pois é "precisamente, porque abre os olhos sobre o que está acontecendo que encontra o acidente, o inesperado, o destino, a túxn. Porque foi este homem do olhar autocrático, aberto sobre as coisas, Édipo caiu na armadilha" (FOUCAULT, 2008, p. 47). Aquele que deve conduzir a cidade até seu porto seguro, encontra (عúpíoncıv) nos sinais que ele desvenda os motivos de seu naufrágio. E o que Édipo não sabe, é que ao acionar a série de investigações políticas, judiciárias e religiosas, que se servem de todos os vestígios e que tentam escapar do jugo dos deuses, são as mesmas que o levarão, mais tarde, à sua queda. Édipo, incapaz de pilota-se a si mesmo está, também, impedido de comandar a cidade. E como um piloto que não mais desvenda os sinais da natureza, ele está condenado a navegar por mares desconhecidos para enfim encontrar o seu lugar.

\footnotetext{
${ }_{4}$ Para citar alguns: Montimer Lamson Earle, Jean-Pierre Vernant, Bernard Knox, Pierre Vida-Naquet, Charles Segal.
} 


\section{Curar e pilotar: cuidar de si para cuidar do outro}

Nas rápidas referências que Foucault faz da relação entre medicina e pilotagem, principalmente em seus escritos da década de oitenta, ele parece confirmar o que pensam Detienne e Vernant, quando estes asseguram que "nenhum saber parece mostrar mais afinidades com a arte da navegação do que a do médico" (2008, p. 281). Ademais, indica o pensador francês, que de tão recorrente, tal relação produziu uma série de conceitos e de noções que foram determinantes para o pensamento político, que se estenderam da antiguidade até os séculos XVII e XVIII, pois,

o Príncipe, na medida em que deve governar os outros, governar a si mesmo, curar os males da cidade, os males dos cidadãos, seus próprios males; aquele que governa a si como se governa uma cidade, curando seus próprios males; o médico, que deve emitir pareceres não somente sobre os males do corpo como também sobre os males da alma dos indivíduos (FOUCAULT, 2006, p. 303-304).

Em sua aproximação com a medicina, a pilotagem é, sobretudo, uma téxvn entendida como uma habilidade; uma capacidade de operar um tipo de saber dirigido aos outros, como lemos na carta 84 de Sêneca, quando ele afirma que “[...] a arte de piloto é um bem virado para o exterior, pois diz respeito ao transporte de passageiros, tal como a arte do médico concerne aos doentes que cura" (2004, p. 394). O mesmo sentido recupera Foucault em suas conferências pronunciadas na Universidade Berkeley em 1983, onde mostra, ao comparar a pilotagem e a medicina ao problema da parresía, que as três não dizem respeito a uma atitude pessoal, a uma qualidade ou a uma virtude, mas a algo que necessita de um conhecimento teórico, ao mesmo tempo que demanda um treinamento prático para torna-se útil.

Nesse sentido, uma característica comum aos pilotos e aos médicos, mas também para

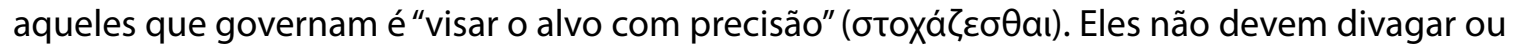
desviar seus olhos, mas mantê-los firmes, mostrando-se detentores de um saber aproximado que abre caminho por rotas desconhecidas em vista de alcançar um ponto no horizonte lon-

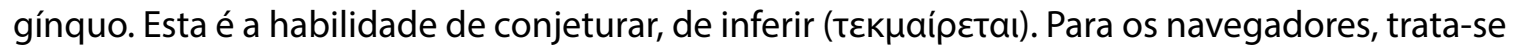
da destreza de se fixar no destino que se almeja, tendo os olhos atentos aos sinais vindos do céu. Para o médico, se traduz na capacidade de se mover de forma rápida e segura entre os sintomas polimorfos que podem afligir um doente, sabendo exatamente qual é o momento certo (кaıрóc) para fazer a intervenção. Por fim, a clarividência política é resultado exatamente da disposição de enxergar o alvo distante e para nele chegar saber agir com agilidade, segurança e escolhendo o melhor momento.

O кaıpóc que é, recorda Foucault, na antiguidade, o ponto em comum entre pilotar e curar uma enfermidade, diz respeito, por sua vez, a compreender os dados particulares, as singularidades, ou seja, as especificidades de cada situação e como em cada uma delas se deve agir. Assim, a medicina e a pilotagem são técnicas que se ocupam das circunstâncias individuais e da escolha do instante certo. Mas também se caracterizam por serem dois gêneros de técnicas onde "uma só pessoa deve decidir, dar as ordens, exercer o poder, e os outros, os doentes, a tripulação, os passageiros do barco, devem obedecer" (FOUCAULT, 2016, p. 226). E é nesse aspecto, que ambas se aproximam da política, pois o governante também "deve ter em conta as circunstâncias, o kaıpóc, um certo tipo de relação de poder pelo qual somente um decide e os outros obedecem" (FOUCAULT, 2016, p. 226).

É a destreza e a agilidade de espírito que possibilitam que piloto e médico atendam a um pedido de socorro quando alguém está em perigo. A expressão grega é ßonӨóc. Foucault recorda que "originalmente, no vocabulário arcaico, ßonӨóc significa socorro. Isto é, o fato de 
que alguém responde ao apelo (boés) lançado pelo guerreiro. E quem lhe traz socorro responde com um grito, anunciando-lhe que está trazendo socorro e que acorre para ajudá-lo" (2006, p. 390). Da mesma forma que o médico, como indica Marco Aurélio, precisa ter "sempre à mão os instrumentos e ferros para os casos imprevistos" (III, 13), o piloto deve manter o controle do leme e deixar todos os tripulantes em seus lugares e preparados, pois nunca se sabe quando algo pode acontecer para aquele que está em alto mar.

Sabemos que nenhuma téxvn pode ser adquirida sem exercício, sem treino, da mesma forma que todas elas são, mais cedo ou mais tarde, colocadas à prova. Isso é o que vemos num importante trecho de um texto-referência sobre o assunto que é o L'Ancienne médecine de Hipócrates, onde para que um médico cometa o menor número de erros possíveis, ele precisa de um longo e árduo trabalho de preparação e que não são os casos fáceis de serem tratados que testarão o seu saber. O mesmo acontece com os pilotos:"Enquanto estes pilotam em tempo calmo, ao cometerem um erro, o erro não aparece". Ambos, médico e piloto são provados, ou seja, mostrarão sua inabilidade ou, quem sabe, inexperiência somente quando forem confrontados com os eventos mais difíceis; por exemplo, um médico diante de um doente com uma enfermidade complicada para ser curada ou um piloto, com seu navio em meio a uma tempestade ou com os ventos contrários. Já em Institution oratoire de Quintiliano, outro texto-referência, o problema não está em se o médico ou o piloto são colocados à prova por eventos difíceis - o que parece ser inevitável mas sim, que esses acontecimentos inesperados, quando aparecem, não afetam o domínio de sua tદ́xvn ou mesmo a sua reputação, desde que eles tenham "seguido inteiramente as regras" ou seja, tenham realizado seu trabalho com o máximo de esforço e de competência.

\section{Considerações finais}

Com este trabalho, quisemos mostrar como a metáfora da pilotagem, apesar de incidental, torna-se um elemento significativo para a compreensão do problema da governamentalidade no pensamento de Foucault.

Tomando de suas próprias análises as três atividades que se aproximam da arte de comandar um navio na antiguidade greco-romana - o governo sobre si mesmo, o governo político e a medicina - vemos como o ofício do piloto encontra-se entre uma tékhne tou bíou, ou seja, uma arte de viver e uma tékhne, entendida como uma habilidade, destinada profissionalmente aos outros. Nesse sentido, diferentemente da tékhne moderna, onde para governar os outros não é exigido um governo sobre si, na antiguidade, pelo contrário, é preciso primeiramente pilotar-se, para depois assumir o leme e conduzir os outros com segurança.

Passados mais de dois mil e quinhentos anos, vemos como a metáfora da pilotagem relacionada à governamentalidade continua atual, pois em meio à uma pandemia, que tem gerado uma crise social, econômica e política sem precedentes, constatamos, cada vez mais, a necessidade de termos um "capitão" com as capacidades e as habilidades de conduzir essa grande embarcação que está à deriva - o Brasil - até um porto seguro.

\section{Referências}

AURELIO, Marco. Meditaciones. Madrid: Editorial Gredos, 1977.

DAREMBERG, Charles Victor; SAGLIO, Edmond. Dictionnaire des Antiquités Grecques et Romaines. Paris: Hachett Livre, 1919. 
DETIENNE, Marcel;VERNANT, Jean-Pierre. Métis. As astúcias da inteligência. São Paulo: Odysseus Editora, 2008.

ÉSQUILO. Sete contra Tebas. São Paulo: Editora 34, 2018.

FOUCAULT, Michel. A hermenêutica do Sujeito. São Paulo: Martins Fontes, 2006.

FOUCAULT, Michel. A verdade e as formas jurídicas. Rio de Janeiro: Nau, 2008.

FOUCAULT, Michel. Discours et vérité. Paris: Vrin, 2016.

FOUCAULT, Michel. Leçons sur la volonté de savoir. Cours au Collège de France 1970-1971. Paris: Gallimard/Seuil, 2011.

FOUCAULT, Michel. Mal faire, dire vrai. Fonction de l'aveu em justice. Louvain: Press universitaire de Louvain, 2012.

GLOTZ, Gustave. L'ordalie dans la Grèce primitive: Étude de droit et de mythologie. Paris: Albert Fontemoing Éditeur, 1904.

HIPPOCRATES. L'Ancienne médecine. Londres: William Heinemann, 1942.

LAMPE, Geoffrey William Hugo. A Patristic Greek Lexicon. Oxford: Claredon Press, 1961.

LIDDELL, Henry; SCOTT, Robert. A Greek-English Lexicon. Oxford: Claredon Press, 1996.

ONELLY, Glória Braga. A ideologia aristocrática nos Theognidea. Niterói: Ed. UFF, 2009.

PLATÃO. A República. Lisboa: Fundação Calouste Gulbenkian, 2005.

QUINTILIANO, Marco Fabio. L'istituzione oratória. Torino: Unione Tipografico-Editrice Torinese, 1968.

RAGUSA, Giuliana. Lira grega. São Paulo: Hedra, 2014.

SÊNECA, Lúcio Aneu. Cartas a Lucílio. Lisboa: Fundação Calouste Gulbenkian, 2004.

SÓFOCLES. Édipo-Rei. Rio de Janeiro: Lamparina, 2004.

SÓFOCLES. Édipo-Rei. São Paulo: Perspectiva, 2012.

\section{Sobre o autor}

\section{Fabiano Incerti}

Doutor em Filosofia pela PUCSP. Professor do Programa de Pós-graduação em Filosofia da PUCPR, atuando na área de Ética e Filosofia Política.

Recebido em: 29/06/2020.

Aprovado em: 27/09/2020.
Received: 29/06/2020.

Approved: 27/09/2020. 